Be happy and believe in your capacity: Establishing link between subjective well-being and self-efficacy among Filipino adolescents

Datu, Jesus Alfonso

De La Salle University, Manila, Philippines (jess.datu@yahoo.com)

Received: 25 August 2012

Available Online: 17 September 2012
Revised: 9 September 2012 DOI: $10.5861 /$ ijrsp.2012.206

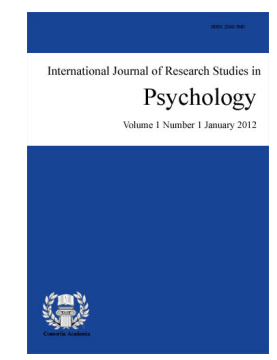

ISSN: $2243-7681$ Online ISSN: 2243-769X

Accepted: 11 September 2012

OPEN ACCESS

\title{
Abstract
}

The study describes the relationship between the degree of subjective well-being and level of self-efficacy among the intended populace. Two hundred adolescents (131 female and 69 male) who were part of the larger population of individuals whose age ranges from 15 to 19 in a private sectarian college were selected and asked to answer Oxford Happiness Questionnaire (OHQ) and General Self Efficacy Scale (GSE). The study employed a descriptive-correlational research design. After collecting the questionnaires among the subjects and analyzing the data using SPSS 17.0 software, it was revealed that subjective well-being is significantly related to self-efficacy $(\mathrm{r}=.32, p<.01)$. The researcher also looked into the possible implications of this finding to the population at hand.

Keywords: adolescents; positive psychology; self-efficacy; subjective well-being 


\section{Be happy and believe in your capacity: Establishing link between subjective well-being and self-efficacy among Filipino adolescents}

\section{Introduction}

Happiness is one of the most enthusiastic and scintillating concepts in the field of behavioral sciences. In fact, it is a very difficult term which incorporates an immense array of human experiences ranging from ecstasy to mild pleasure, from sense of fulfillment and worth to a fleeting smile or laugh. It is not a quantity that can be easily measured, or a construct that can be outlined without ambiguity as it encompasses subjective perceptions of well-being. It refers to the degree to which an individual judges the overall quality of his own life as a whole (Peterson, Park \& Seligman, 2005; Seligman, 2002; Veenhoven, 2001). It also talks about one of the multifarious dimensions of Positive Psychology (Huppert, 2006; Seligman \& Csikszentmihalyi, 2000). With its incessant and evolving progress, positive psychology proclaims that the main goal of their efforts is to make people happy (Seligman \& Csikszentmihalyi, 2000). This notion is not hard to believe as it talks about a positive intrinsic attribute that a human being can ever possess.

There are a number of precursors to the attainment of happiness (Veenhoven, 2007). On a national level, happiness is normally predicted by the existence of certain aspects regarding societal concerns. Security, freedom, equality, cultural and social climate, population pressure and modernity follow suit. As to a more microcosmic measure of happiness, it is social ties that account for a great degree of variability on happiness reports. Intimate ties follow closely, whilst others such as social status, age, gender, income, education, occupations and social participation bring up the latter part of the list (Lent, Singley, Sheu, Gainor, Brenner, Treistman, \& Ades, 2005; Veenhoven, 2001, 2003, 2006, 2007). In one way or another, this will suffice the notion that majority of man's efforts are directed towards making people happier than they get used to. In relation to the myriad of possible elucidations to delve on this humanistic concept, Seligman, Parks \& Steen (2004) described happiness as "the very thing which makes life worth living". It fortifies one of its psychological definitions which stated that it is a positive joyous state as gauged by one's subjective perception.

In contrast, self-efficacy is a psychological concept which encompasses individualistic adaptive capabilities. It refers to peculiar ways by which people act in various situations which depends on the reciprocity of behavioral, environmental and cognitive conditions. Bandura (2001) defined self-efficacy as "people's beliefs in their capability to exercise some measure of control over environmental events." It encompasses people's confidence that they have the ability to perform certain behaviors. Research has reported as well that self-efficacy is related to physical and mental health (Crisp, 2005). Lyubomirsky, King, and Diener (2005) discerned that positive moods or happiness is salient in thinking, feeling and acting in ways that encourage resource and building and involvement with particular goal materialization. Moreover, self-efficacy was predominantly linked to subjective well-being (Caprara \& Steca, 2005; Diener, Oishi, \& Lucas, 2003; Fogle, Huebner \& Laughlin, 2002; Lent, 2004; Lent, Singley, Sheu, Gainor, Brenner, Treistman, \& Ades, 2005). Likewise, Bandura (2001) averred that self-sufficiency can be acquired, enhanced or decreased through any one or combination of four sources namely: (1) mastery experiences; (2) social modeling; (3) social persuasion; and (4) physical and emotional states. As such, behaviors can be predicted by one of the aforementioned factors.

As demarcated by past studies, adolescents with low self-efficacy are more susceptible to experience stress since new psychosocial demands and developmental tasks are expected from them (Bandura, 1995). In contrast, studies from individualistic societies have revealed that self-efficacy beliefs positively impacted academic achievement (Bandura, Barbaranelli, Caprara, \& Pastorellim, 1996), prosocial behaviors (Bandura, Caprara, Barbaranelli, Gerbino, \& Pastorelli, 2003) and career selection (Bandura, Barbaranelli, Caprara, \& Pastorelli, 2001). However, given that such inquiries were done in the Western context and the manner by which Western individuals are making sense of their selves in the context of other people is essentially different from people in 
the Asian context (Markus \& Kitayama, 1991), it may be not appropriate to say that the findings and inferences from such studies can be practically applied in collectivistic societies.

The current study, therefore, was conceptualized as an attempt to look into the possible relationship that can be deduced from respondents' degree of happiness and level of self-efficacy in the Philippine context. The researcher sought to scrutinize how it would affect the positive joyous state and perceived abilities to perform various tasks of individuals. Given that emotional states is believed to be one of the substrates of self-efficacy (Bandura, 2001), this paper investigated the link between such constructs. Specifically, it examined relationship between the respondents' degree of happiness and level of self efficacy. Possible implications to the population at hand were also integrated in the analysis.

\section{Methodology}

\subsection{Research design}

The study utilized a descriptive-correlational research design. Banyard and Grayson (2001) defined correlational research as a type of study that is designed to measure and describe the relationship between two variables without attempting to explain the cause of the relationship. In the present study, happiness served as the predictor variable while self-efficacy served as the criterion variable.

\subsection{Participants}

Two hundred students (69 males, 131 females) aged 15-19 $(M=16.35, S D=1.35)$ from a private sectarian collegiate institution in Metro Manila (major metropolis area of the Philippines) were chosen as participants of the study. Majority of them are taking up Business Management (27.5\%) followed by Psychology (36.5\%), Communication Arts (15.5\%) and Hospitality Management (21.5\%).

\subsection{Research instrument}

The researcher utilized Oxford Happiness Questionnaire (OHQ) and General Self-Efficacy Scale (GSE) as data gathering instruments. Hills and Argyle (2002) developed the 29-item Oxford Happiness Questionnaire to assess subjective well-being which includes Likert scale of 1 to 6 . Higher scores will signify elevated degree of happiness. Current reliability of the said test is 0.85 . General Self-Efficacy Scale (Shwarzer et al., 2002) is a 10 -item scale designed to assess optimistic self-beliefs used to cope with a variety of demands in life. The scale was designed to assess self efficacy. The scaled score for each question ranges from 1 to 4 . Higher scores indicate stronger belief in self-efficacy. Its current reliability is $\alpha=.87$.

\section{Results}

Table 1, summarizes information relevant to the profile of the first instrument that was administered to them. It reports the means and standard deviations for all the responses of the two hundred respondents on the Oxford Happiness Questionnaires. For the purpose of convenient interpretation, a total mean rating of 2.5 (on the 6-point scale) was taken to indicate unhappiness. On the other hand, a total mean rating of 3.0 suggested moderate degree of happiness. Likewise, a total mean rating of above 3.0 implied high degree of happiness.

As can be observed in Table 1, there are scores in some items that could be significant in the respondents' overall degree of subjective well-being. For instance, item no. 9 (Life is good) garnered the highest mean rating $(M=5.37, S D=.90)$ which talks about their degree of optimism in life. Likewise, item no. 11 (I laugh a lot) occupied the second highest mean rating $(M=5.03, S D=1.15)$ which pertains to the respondents inclination to positive emotions. Even the aesthetic dimension of subjective- well-being appeared to be prevalent $(M=4.99$, $S D=.81$ ). Their low score in item no. 27 (I don't have fun with other people) was also consistent to his high 
Datu, J. A.

score in item no. 11 which implies humor.

Table 1

Descriptive statistics for Oxford happiness questionnaire items

\begin{tabular}{lc}
\multicolumn{1}{c}{ Items } & $\mathrm{M}$ \\
\hline & $S D$ \\
\hline 1. I don't feel particularly pleased with the way I am & 2.79 \\
2. I am intensely interested in other people & 4.47 \\
3. I feel that life is very rewarding. & 4.90 \\
4. I have very warm feelings towards almost everyone. & 4.30 \\
5. I rarely wake up feeling rested. & 3.61 \\
6. I am not particularly optimistic about the future. & 2.99 \\
7. I find most things amusing. & 4.53 \\
8. I am always committed and involved. & 3.87 \\
9. Life is good. & 5.37 \\
10. I do not think that the world is a good place. & 2.48 \\
11. I laugh a lot. & 5.03 \\
12. I am well satisfied about everything in my life. & 4.36 \\
13. I don't think I look attractive. & 3.22 \\
14. There is a gap between what I would like to do and what I have done. & 3.93 \\
15. I am very happy. & 4.78 \\
16. I find beauty in some things. & 4.99 \\
17. I always have a cheerful effect on others. & 4.56 \\
18. I can fit in (find time for) everything I want to. & 4.18 \\
19. I feel that I am not especially in control of my life. & 3.30 \\
20. I feel able to take anything on. & 3.94 \\
21. I feel fully mentally alert. & 4.06 \\
22. I often experience joy and elation. & 4.41 \\
23. I don't find it easy to make decisions. & 4.10 \\
24. I don't have a particular sense of meaning and purpose in my life. \\
25. I feel I have a great deal of energy. & 2.67 \\
26. I usually have a good influence on events. & 4.58 \\
27. I don't have fun with other people. & 4.39 \\
28. I don't feel particularly healthy. & 2.12 \\
29. I don't have particularly happy memories of the past. & 2.88 \\
\hline
\end{tabular}

Table 2

Descriptive statistics for Oxford happiness questionnaire for the full sample $(N=200)$

\begin{tabular}{ccccc}
\hline Item & $N$ & $\mathrm{M}$ & $S D$ & Interpretation \\
\hline Happiness & 200 & 3.90 & .43 & Very happy \\
\hline
\end{tabular}

Using the previously stated criteria, it is can be noticed data that the respondents were very happy as accentuated by their total mean rating of 3.90. The standard deviation for all their responses was only 0.43 , which actually talked about the homogeneity of their responses. Hence, it can be observed that their responses are relatively close to each other. While, Table 3 shows the means and standard deviation values of the responses gathered from the respondents of the study to the General Self-Efficacy Scale. For the intention expedient interpretation, the researcher a total mean rating below 2.0 (on the 4-point scale) was taken to indicate low self-efficacy. On the other hand, a total mean rating of 2.0 suggested moderate or average level of self-efficacy. Likewise, a total mean rating of above 2.0 implied high degree of self-efficacy.

Bearing in mind such statistical criteria, it may be empirically deduced from the respondents that they have high degree of perceived capabilities to accomplish wide spectrum of tasks as evidenced by the total mean score of 2.92 which is noticeably justified by the previous range of values defined by the researcher $(M>2.0)$. The responses were also very homogenous as fortified by its computed standard deviation value which is 0.41 . Therefore, the mean scores per item procure minimal dispersion relative to the total mean gathered from the said 
instrument.

\section{Table 3}

Descriptive statistics for general self-efficacy items

\begin{tabular}{lcc}
\multicolumn{1}{c}{ Item } & $\mathrm{M}$ & $S D$ \\
\hline 1. I don't feel particularly pleased with the way I am & 2.79 & 1.33 \\
2. I am intensely interested in other people & 4.47 & 1.23 \\
3. I feel that life is very rewarding. & 4.90 & 1.27 \\
4. I have very warm feelings towards almost everyone. & 4.30 & 1.51 \\
5. I rarely wake up feeling rested. & 3.61 & 1.13 \\
6. I am not particularly optimistic about the future. & 2.99 & 1.25 \\
7. I find most things amusing. & 4.53 & 0.90 \\
8. I am always committed and involved. & 3.87 & 1.29 \\
9. Life is good. & 5.37 & 1.13 \\
10. I do not think that the world is a good place. & 2.48 & 1.53 \\
\hline
\end{tabular}

\section{Table 4}

Descriptive statistics for general self-efficacy scale for the full sample $(N=200)$

\begin{tabular}{ccccc}
\hline Item & $N$ & M & $S D$ & Interpretation \\
\hline Self-efficacy & 200 & 2.92 & 0.41 & High \\
\hline
\end{tabular}

\subsection{Relationship between subjective well-being and self-efficacy}

Based on the Pearson product-moment correlation coefficient revealed by the Statistical Package for the Social Sciences (SPSS 17.0) Software, the value of $r$ is 0.32 which implies a quite low correlation. Although the value of the correlation coefficient ( $r$ ) is not that high, upon testing for significance specifically at 0.01 alpha levels, it was found out that subjective well-being or happiness is significantly correlated to self-efficacy. The positive correlation would imply that subjective well-being is directly linked to self-efficacy of the sample at hand.

\section{Table 5}

Correlational coefficient between subjective well-being and self-efficacy

\begin{tabular}{lccccc}
\hline \multicolumn{1}{c}{ Items } & $N$ & M & $S D$ & $R$ & $p$ \\
\hline Subjective well-being & 200 & 3.90 & 0.43 & $0.32^{* *}$ & .000 \\
Self-efficacy & 200 & 2.92 & 0.41 & & \\
\hline
\end{tabular}

Note. ${ }^{* *}$ Correlation is significant at the 0.01 level (2-tailed)

\section{Discussion}

The study have illustrated that the respondents have a moderately high degree of subjective well-being and self-efficacy. It is highly accentuated by the descriptive statistical results depicted prior to the responses of the respondents to the Oxford Happiness Questionnaire and General Self-Efficacy Scale. Furthermore, upon thorough analysis on various psychological constructs that some of the items in the Oxford Happiness Questionnaire encompass, the researcher identified optimism, aesthetic appreciation and sense of humor as salient domains that would typify happy individuals which was consistent with previous literature (Caprara \& Steca, 2005).

Most importantly, the study revealed that there is a significant relationship that exists between the respondents' degree of happiness and level of self-efficacy. Although the correlation coefficient is relatively low $(r=0.32, p<.01)$, this still proved to show statistically significant association between the two variables. The link between happiness and self-efficacy seemed to typify realistic premises given that positive affect is predictive of better perception of one's capabilities to carry out spectrum of life tasks. Even though respondents came from a 
collectivistic society, this finding was consistent with the results from past researches done in the Western context (Caprara \& Steca, 2005; Diener, Oishi, \& Lucas, 2003; Fogle, Huebner, \& Laughlin, 2002; Lent, 2004; Lent, Singley, Sheu, Gainor, Brenner, Treistman, \& Ades, 2005). As such, it is imperative for counselors, psychologists, teachers and other concerned professionals to execute collaborative efforts in making adolescent clienteles happy in order to increase the likelihood that they can acquire a better insight as regards to the set of endeavors where they can possible excel given that it is a crucial developmental stage where they are engaged in exploring their respective psychological identities.

Lastly, since the significant relationship that has been established between the respondents' degree of happiness and level of self-efficacy wouldn't be enough to formulate a causal inference, the researcher computed for the proportion by which the variance in the level of self-efficacy can be accounted for the degree of happiness. The coefficient of determination is $\mathrm{r}^{2}=0.10$ which signifies that only $10 \%$ of the variance in the respondents' level of self-efficacy might be attributed to the degree of happiness while the $90 \%$ of the change can be brought about by some other factors that were not included in the study such as personality type, intelligence, self-esteem, emotional stability etc. It is also worth mentioning that the findings have really accentuated Albert Bandura's theory on self-efficacy since he hypothesized that the final source of self-efficacy is the people's physiological and emotional states (Bandura, 2001). In view of the fact that it was illustrated in the study that there is a significant association that exist between the degree of happiness and level of self-efficacy, it proved that a positive finely tuned and joyous emotional state can really foster successful performance of various developmental tasks.

\section{Conclusion}

As can be drawn from the findings of the study, adolescents' level of self-efficacy has a significant relationship with the degree of subjective well-being. By employing a descriptive-correlational research design, the researcher was able to portray how the positive and joyous state of the respondents can influence their perceived sense of personal adequacy. It has been also found out how important various psychological constructs are in the attainment of happiness such as optimism, aesthetic appreciation and sense of humor. With reference to quite low associative coefficient to happiness, it can be inferred that self-efficacy is a multifaceted psychological concept and that a single construct such as happiness could not fully explain it's relatively enduring dimensions. Self-efficacy could be scrutinized with the utilization of other possible relevant variables such as intelligence, personality type, temperament, etc. Nonetheless, it also coheres with Bandura's theory on self-efficacy since it accentuated one of the essential sources of self-efficacy which is the physiological and emotional state such as happiness. Therefore, it can be surmised that experiencing positive emotions like happiness is crucial in the respondents perception of their ability to execute wide array of developmentally-anchored life tasks. This proved to be another input on the part of the growing fund of knowledge in the field of Positive Psychology particularly on the continuous proliferation of researches which encompass the issue of subjective well-being.

The findings will help the counselors, psychologists and educators to understand holistically various factors which could possibly contribute to the improvement of adolescent's perceived level of capacity to perform developmentally-grounded life tasks such as happiness. Likewise, this will also be purposeful in the practice of Guidance and Counseling as it will allow the guidance counselors to assist adolescents in making important choices in their lives, subsequently letting them realize the worth of life in light of their ability to do things efficiently. Designing counseling programs that addresses attainment of positive and joyous condition among adolescent clientele is a sound and viable option in optimizing opportunities to perform tasks that are reflective of their developmental stages.

\section{References:}

Bandura A., Barbaranelli, C., Caprara, G. V., \& Pastorelli, C. (2001). Self-efficacy beliefs as shapers of children's 
aspirations and career trajectories. Child Development, 72, 187-206.

http://dx.doi.org/10.1111/1467-8624.00273

Bandura, A., Caprara, G. V., Barbaranelli, C., Gerbino, M., \& Pastorelli, C. (2003). Role of affective self-regulatory efficacy on diverse spheres of psychosocial functioning. Child Development, 74, 769-782. http://dx.doi.org/10.1111/1467-8624.00567

Bandura, A. (2001). Social cognitive theory and clinical psychology. In N. J. Smelser \& P. B. Baltes (Eds.), International encyclopedia of the social and behavioral sciences, 21, 14250-14254. http://dx.doi.org/10.1016/B0-08-043076-7/01340-1

Bandura, A. (Ed.) (1995). Self-efficacy in changing societies. New York: Cambridge University Press.

Bandura, A., Barbaranelli, C., Caprara, G. V., \& Pastorelli, C. (1996). Multifaceted impact of self-efficacy beliefs on academic functioning. Child Development, 67, 1206-1222. http://dx.doi.org/10.2307/1131888

Banyard, P., \& Grayson A. (2001). Introducing psychological research. New York: Palgrave.

Caprara, G. V., \& Steca, P. (2005). Affective and social self-regulatory efficacy beliefs as determinants of positive thinking and happiness. European Psychologist, 10, 275-286. http://dx.doi.org/10.1027/1016-9040.10.4.275

Crisp, R. (2005). The Stanford encyclopedia of philosophy. In E. N. Zalta (Ed.), Wellbeing (Winter 2005 ed.). Retrieved August 30, 2012, from http://plato.stanford.edu/archives/win2005/entries/wellbeing

Diener, E., Oishi, S., \& Lucas, R. E. (2003). Personality, culture, and subjective well-being: Emotional and cognitive evaluations of life. Annual Review of Psychology, 54, 403-425. http://dx.doi.org/10.1146/annurev.psych.54.101601.145056

Fogle, L. M., Huebner, S. E., \& Laughlin, J. E. (2002). The relationship between temperament and life satisfaction in early adolescence: Cognitive and behavioral mediation models. Journal of Happiness Studies, 3, 373-392. http://dx.doi.org/10.1023/A:1021883830847

Hills, P., \& Argyle, M. (2002). The Oxford Happiness Questionnaire: A compact scale for the measurement of psychological well-being. Personality and Individual Differences, 33, 1073-1082. http://dx.doi.org/10.1016/S0191-8869(01)00213-6

Huppert, F. (2006). Positive emotions and cognition: Developmental neuroscience and health perspectives. In J. Forges (Ed.), Hearts and minds: Affective influences on social cognition and behavior. Philadelphia: Psychology Press.

Hurlock, E. (1982). Developmental psychology: A life-Span approach (5 ${ }^{\text {th }}$ ed.). New York: McGraw-Hill.

Lent, R. W. (2004). Toward a unifying theoretical and practical perspective on well-being and psychosocial adjustment. Journal of Counseling Psychology, 51, 482-509. http://dx.doi.org/10.1037/0022-0167.51.4.482

Lent, R. W., Singley, D., Sheu, H. B., Gainor, K. A., Brenner, B. R., Treistman, D., \& Ades, L. (2005). Social cognitive predictors of domain and life satisfaction: Exploring the theoretical precursors of subjective wellbeing. Journal of Counseling Psychology, 52, 429-442. http://dx.doi.org/10.1037/0022-0167.52.3.429

Luszczynska, A., Gutiérrez-Doña, B., \& Schwarzer, R. (2005). General self-efficacy in various domains of human functioning: Evidence from five countries. International Journal of Psychology, 40(2), 80-89. http://dx.doi.org/10.1080/00207590444000041

Markus, H. R., \& Kitayama, S. (1991). Culture and the self: Implications for cognition, emotion, and motivation. Psychological Review, 98(2), 224-253. http://dx.doi.org/10.1037/0033-295X.98.2.224

Morris, A. S., \& Steinberg L., (2001). Adolescent development. Annual Review of Psychology, 52, 83-110.

Pagano, R. R. (2007). Understanding behavioral statistics in the behavioral sciences (8th ed.). Belmont, CA: Wadsworth.

Peterson, C., Park, N., \& Seligman, M. E. (2005). Orientations to happiness and life satisfaction: The full life versus the empty life. Journal of Happiness Studies, 6, 25-41. http://dx.doi.org/10.1007/s10902-004-1278-z

Rimm, H., \& Jerusalem, M. (1999). Adaptation and validation of an Estonian version of the General Self-Efficacy Scale (ESES). Anxiety, Stress, and Coping, 12, 329-345. 
Datu, J. A.

http://dx.doi.org/10.1080/10615809908250481

Seligman, M. (2002). Authentic happiness. New York: Free Press.

Seligman, M. P., \& Csikszentmihalyi, M. (2000). Positive psychology: An introduction. American Psychology, 55, 5-14. http://dx.doi.org/10.1037/0003-066X.55.1.5

Veenhoven, R. (2001). What we know about Happiness. Retrieved January 14, 2001 from http://www.eur.nl/fsw/research/veenhoven4

Veenhoven, R. (2003). Notions of art-of-living. Journal of Happiness Studies, 4(4), 345-349. http://dx.doi.org/10.1023/B:JOHS.0000005771.22194.08

Veenhoven, R. (2006). Trend average happiness in nations 1946-2004. World Database of Happiness, Trend report 2006-1. Available July 15, 2012, from http://worlddatabaseofhappiness.eur.nl/hap_nat/findingreports/2006-1.pdf

Veenhoven, R. (2007). Measures of gross national happiness. MPRA Paper 11280, University Library of Munich, Germany. Retrieved July 15, 2012, from http://ideas.repec.org/e/pve145.html 